\title{
Development Status of International Standards on the Rail Track and the Trend of the Related Research of RTRI
}

\author{
Katsumi MURAMOTO \\ Track Technology Division
}

\begin{abstract}
The railway business is now one of the global growth industries. Even in Japan, overseas deployment of railway technology including the Indian high-speed railway is rapidly progressing, but the difference between European forces preceding in international standards and Japan is still large. Therefore, in order to respond to the further globalization of the railway business, Japan must also actively participate in international standard development. In this paper, the author introduce the activities of RTRI's track technology department for the development of the rail track international standards.
\end{abstract}

Keywords: international standards, ISO, TC 269, EN

\section{Introduction}

Unlike in the distant past when it was called a declining domestic industry, the railway today is certainly one of the globally growing industries. In Japan, JICA, JR companies and relevant manufacturers have been playing the leading role in accelerating the export of Japan's railway technologies, as exemplified by the high-speed rail project in India. On international standardization, European players are still far ahead of Japan. That is especially true regarding tracks where the European standards (hereafter "EN" ) are currently the de facto global standards. Consequently, technical standards that are used in many countries are based on EN.

While Japanese players accelerate expansion to overseas markets, the import of overseas railway technologies are going to grow as well under WTO's TBT Agreement (agreement on Technical Barriers to Trade) and GP Agreement (agreement on Government Procurement). In any event, the days of the railway industry catering only to the domestic market are long gone, with Today's railway industry further accelerating globalization and for that matter international standardization.

\section{Outline of international standardization on infra- structure}

On the international standardization of railway infrastructure, ISO (International Organization for Standardization)'s TC 269 (Technical Committee on railway applications, founded in 2012) is in charge. Three SCs (Subcommittees) including SC 1 (Infrastructure) were launched in June 2016. Since its launch, SC 1 has been actively developing international standards on tracks, setting up five WGs (Working Groups) less than two years from launch. The entire ISO/TC 269 structure including the other SCs is shown in Fig. 1. On SC 1, Japan is leading two units: WG 1 (Plastic sleepers) and WG 3 (Rail welding). Of tracks-related international standards, those related to rails are handled by ISO/TC 17/SC 15 (Railway rails, rails fasteners, wheels and wheelsets) as of 2017.

On the domestic front, the ISO/TC 269 infrastructure working group set up in February 2013 was succeeded in April 2016 by into the ISO/TC 269/SC 1 committee as the responsible deliberation body. The committee is primarily composed of experts on tracks from RTRI's Railway International Standards Center, which is the secretariat, the Japanese government, railway operators, manufacturers and consultants. The committee is tasked with, among other things, selecting international experts representing Japan in ISO/TC 269/SC 1 working groups and collating policies, proposals, opinions, etc. of Japan to present at ISO/TC 269 general assemblies and working groups.

\section{RTRI's involvement in international standardiza- tion on tracks}

Because ISO/TC 269/SC 1 is actively working on the development of international standards on tracks as explained earlier, RTRI's Tracks Technology Division has been playing the leading role by sending experts to all of the SC 1 working groups. RTRI has also been focusing on the publication of technical documents in the English language as well as presentations at international meetings, all of which support Japanese representatives when they present opinions and proposals. The rest of this section outlines each working group's activities.

\subsection{Plastic sleepers}

The development of standards for plastic sleepers started in 2008 by ISO/ TC 61/SC 11/WG 9 (Plastics TC / Products SC/Plastic sleepers WG) and, as part of the efforts, ISO 12856 Part 1 Material characteristics was released in March 2014. Subsequently, ISO/TC 269/SC 1 took over ISO/ TC 61/SC 11/WG 9 and currently the committee's WG 1 (Plastic sleepers) is developing standards for ISO 12856 Part 2 Products testing.

In Japan, a synthetic sleeper (made of rigid urethane foam reinforced with glass long fiber) for practical applications was developed around 1980 by the R\&D arm of the now-defunct Japanese National Railways. Since then, the sleeper's use on commercial lines has proven its durability. This is just an example of the huge lead Japan has main- 


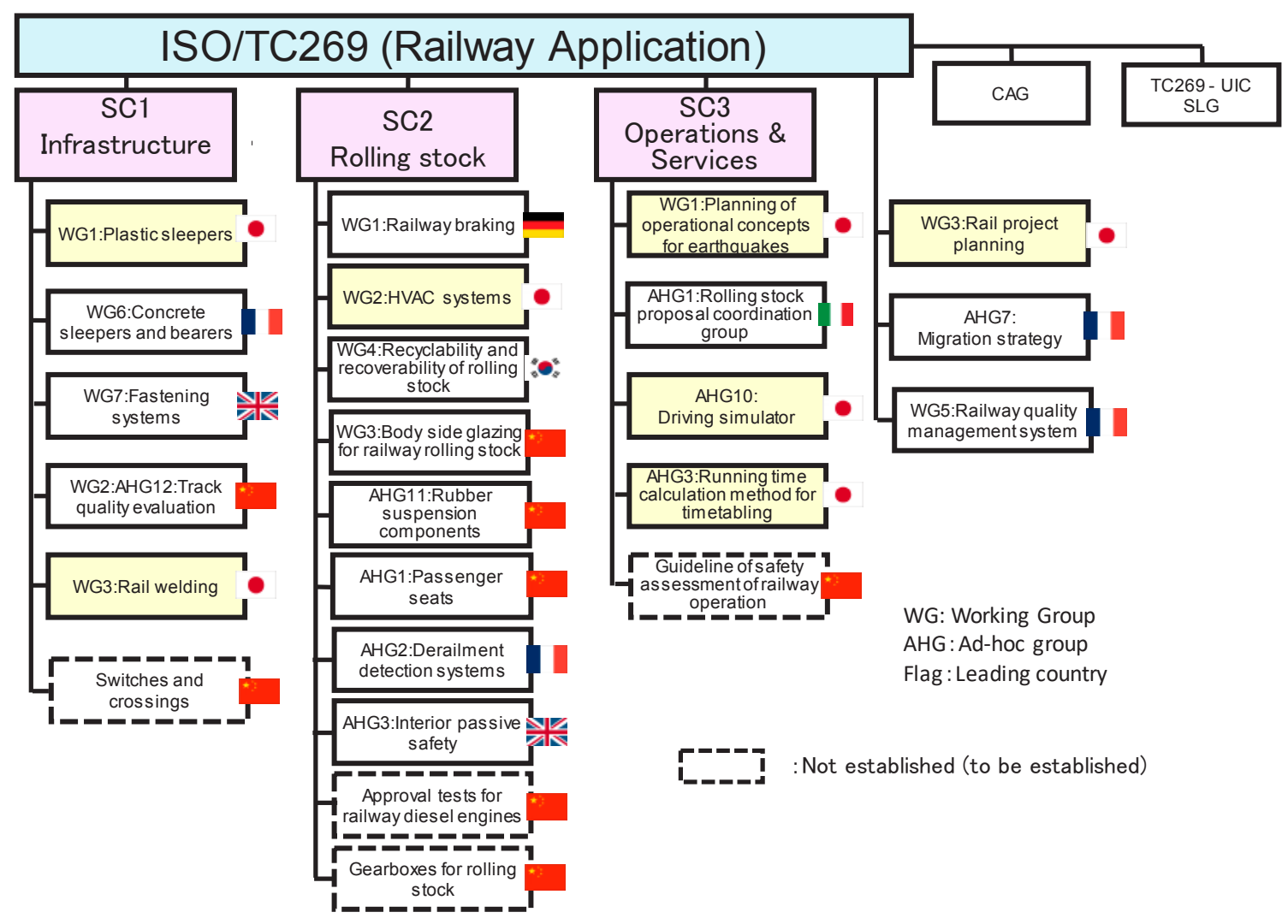

Fig. 1 Entire ISO/TC 269 structure (as of July 2018)

tained over other countries in plastic sleepers technology and market performance. The lead, however, means that performance requirements and test methods used in Japan are vastly different from those adopted in other countries. It is far from certain whether the test methods that Japan has been using for many years would be accepted as international standards. In the future, it is anticipated that Japanese manufacturers of synthetic sleepers would expand overseas and/or less expensive foreign products would be adopted by Japanese railway operators. Therefore, on ISO 12856 Part 2, we are going with that in mind and to ensure that relevant parties in Japan and foreign countries both benefit from the developed standards.

\subsection{Concrete sleepers}

On concrete sleepers standards, ISO/TC 269/SC 1/WG 6 (Concrete sleepers and bearers) was set up in May 2017 following relevant proposals from Europe. The development of relevant international standards will be pursued based on EN 13230 shown in Table 1. It is considered highly likely that migration strategy would be proposed by Europe on EN 13230 series, thereby cutting the time required for standardization.

On the international standardization of concrete sleepers, repetitive fatigue test, which is included in EN, can be a significant issue for Japan. Prestressed concrete sleepers used in Japan are subjected to lighter axle load than sleepers overseas and their cross sections are designed to retain a fully prestressed state. For those reasons, the fluctuating stress that the steel members are subjected to under train
Table 1 EN 13230 series

\begin{tabular}{|l|l|}
\hline Standard No. & $\begin{array}{l}\text { Railway applications: Track - Concrete } \\
\text { sleepers and bearers }\end{array}$ \\
\hline \hline EN 13230-1 & Part 1: General requirements \\
\hline EN 13230-2 & $\begin{array}{l}\text { Part 2: Prestressed monoblock } \\
\text { sleepers }\end{array}$ \\
\hline EN 13230-3 & Part 3: Twin-block reinforced sleepers \\
\hline EN 13230-4 & $\begin{array}{l}\text { Part 4: Prestressed bearers for } \\
\text { switches and crossings }\end{array}$ \\
\hline EN 13230-5 & Part 5: Special elements \\
\hline EN 13230-6 & Part 6: Design \\
\hline
\end{tabular}

load is sufficiently low and the sleepers are more difficult to crack. Therefore, fatigue is not a consideration when using prestressed concrete sleepers in Japan. On the other hand, it appears unlikely that the fatigue test, which has been adopted in EN, would be excluded from international standards. Accordingly, we will insist on actual performance of Japan and scientific basis so that quantitative conditions for skipping the fatigue test can be included in the standard of the concrete sleepers.

\subsection{Fastening systems}

On fastening systems, in January 2017 ISO/TC 269/ SC 1 set up WG 7 (Fastening systems) to start the development of international standards as ISO 22074 series. It is anticipated that international standards for fastening 
Table 2 Comparison of repetitive loading test between Japanese standards and EN

\begin{tabular}{|c|l|l|}
\hline & \multicolumn{1}{|c|}{ Japan } & EN \\
\hline Standards & $\begin{array}{l}\text { Design standards for railway structures } \\
\text { (Track structure) }\end{array}$ & EN 13146-4 \\
\hline $\begin{array}{c}\text { Loading } \\
\text { conditions }\end{array}$ & $\begin{array}{l}\text { Set up for specific conditions in which } \\
\text { fastening systems are used }\end{array}$ & $\begin{array}{l}\text { Set up for each category of fastening } \\
\text { systems }\end{array}$ \\
\hline Loading methods & $\begin{array}{l}\text { None } \\
\text { Note: Dual-rod alternate loading is } \\
\text { normally used. }\end{array}$ & Single-rod loading \\
\hline Times of loading & 1 million & 3 million \\
\hline $\begin{array}{c}\text { Performance } \\
\text { inspection item }\end{array}$ & $\begin{array}{l}\text { - Rail displacement } \\
\text { - Spring clip stress }\end{array}$ & None \\
\hline
\end{tabular}

systems would be largely based on EN 13146 series for test methods and EN 13481 series for performance requirements. The development process is expected to start with Part 1 Terms and definitions, and then move onto deliberation of subsequent portions including Part 2 based on EN 13146 series for test methods. Among the testing on fastening systems, repetitive loading test and commercial line test can be significant issues for Japan. Table 2 shows comparison of repetitive loading test on fastening systems between the design standards for railway structures used in Japan (hereafter "the design standards" ) and EN. In Japan, inspection of fastening systems for performance against fatigue failure is conducted using Load A (very rare extreme load) and Load B (frequent maximum load) set up for specific track conditions by means of dual-rod alternate loading between Load A and Load B (Fig. 2), which is not specified in the design standards though. On the other hand, repetitive loading test of EN is conducted using loading conditions set up for each of passenger transport, freight transport and other categories, by means of singlerod loading (Fig. 3), not for fatigue but primarily for damage and other external conditions of the components. While this is not specified in the design standards of Japan, EN requires railway operators to undergo commercial line test, specified numbers of times, for a certain period, for each of the categories for subsequent external visual inspection to verify usability etc.

Described above are some of the differences that exist in fastening systems test between the design standards of Japan and EN. Japan would suffer disadvantages if EN in its current form were adopted as the international standards. Given the above, the start of deliberation on Part

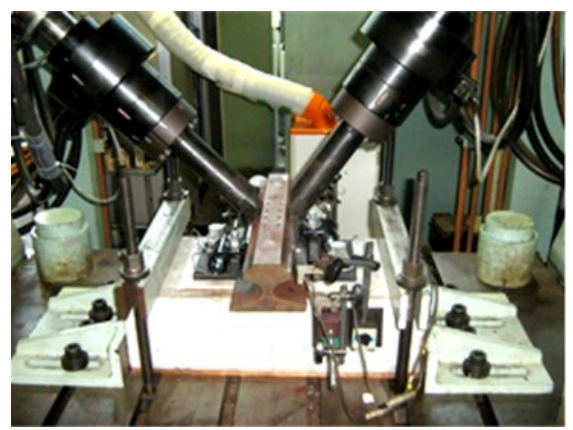

Fig. 2 Dual-rod alternate loading

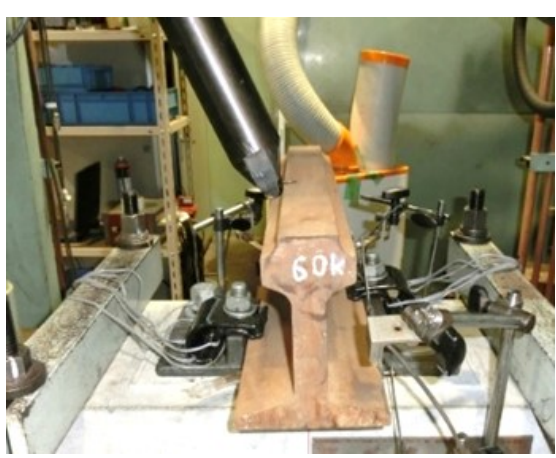

Fig. 3 Single-rod loading

2 and subsequent portions, RTRI has been insisted on the technical legitimacy of the Japanese inspection method at the international meetings etc.[1,2] so that the Japanese concept is adequately reflected in the international standards. In addition, we are organizing the de facto domestic standards not currently specified in the design standards as technical documents.

\subsection{Track quality evaluation}

Following the October 2015 Chinese proposal to establish international standards for track quality measurement,the following three sets of standards were proposed in an ad hoc group.

1) Track Geometry Quality

2) Rail Condition

3) Track Structure

From practical points of view, however, those three areas should be handled as separate standards; in particular, the third area has been regarded as being extremely challenging to standardize by member countries.

Consequently, WG 2 based on EN 13848 series (Track geometry quality) has been set up as "track quality evaluation” in November 2017. In EN 13848 series, which does not include the versine-chord method used in Japan, absolute waveforms obtained from track measurement that have flat frequency characteristics are put through three wavelength band pass filters, D1 (3 - $25 \mathrm{~m})$, D2 (25 - 70 $\mathrm{m})$ and D3 (70 - $150 \mathrm{~m})$, and the output is used as control parameters. Like other international standards, if the current EN-based deliberation for standardization leads to 


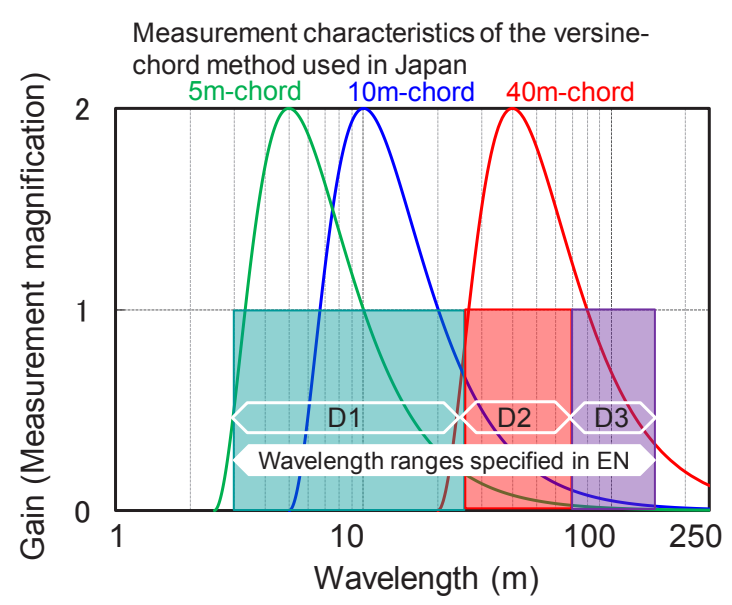

Fig. 4 Difference in track geometry measurement characteristics between Japanese standards and EN

the exclusion of the versine-chord method, the Japanese inspection standards can become invalid. RTRI has been working to obtain agreement from other countries to include the versine-chord method as an option for track geometry control at international meetings and other opportunities[3] by arguing that; although there are differences in track geometry measurement characteristics between the method and EN, no significant difference exist in concerned wavelength bands between them , as shown in Fig. 4, so that the two are practically equivalent to each other.

\subsection{Rail welding}

Gas pressure rail welding, a technique developed in Japan, offers high quality and portability, making it a promising rail welding option for adoption in other countries. EN standards for rail welding include:

1) EN14587 series: Flash butt welding

2) EN14730 series: Aluminothermic welding

3) EN15594: Electric arc welding

4) EN16771: Aluminothermic welding of grooved rails

Gas pressure rail welding, which is widely used in Japan including for Shinkansen, is not included in the list. Any proposal for international standardization of rail welding in such circumstances would have led to EN-based deliberation, possibly resulting in the exclusion of gas pressure rail welding from the final standards. If gas pressure rail welding were excluded from international standards, the technique's chances of adoption overseas would be limited and the use of the technique at domestic railway operators covered by government procurement schemes would also be restricted.

Out of those concerns, to set up a working group led by Japan for international standardization of rail welding with the aim of including gas pressure rail welding in the final standards, exchanges of opinions and presentations with experts or other relevant parties inside and outside Japan on international standardization have been held since 2015. As a result of those efforts, the March 2018 plenary session of ISO/TC 269/SC 1 voted to set up WG 3 (Rail welding) with Japan as its leader for the development of international standards for rail welding.

Like other areas, the development of rail welding standards will start with Part 1 consisting of terms and definitions and general requirements specifying the scope of standards. The current, proposed structure of standards is shown in Fig. 5. To allow flexibility in the development process, the standards are structured not based on individual techniques but based on the following: Forging System whereby base materials are directly joined together without any other material, Casting System whereby filler materials are used to join the base material, and Future New Technology. Currently, we are going to obtain the understanding of other relevant countries on the development plans based on the proposed structure.

RTRI will keep striving to gain higher recognition from other countries regarding Japan's rail welding technology, including gas pressure rail welding, by presenting high-

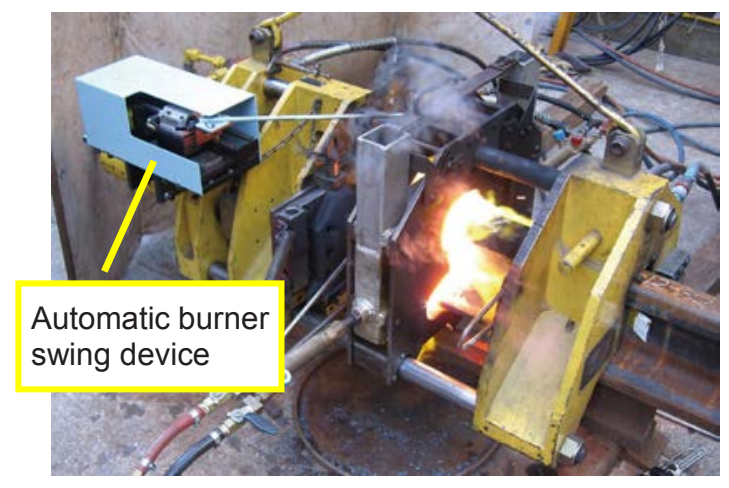

Fig. 6 Gas pressure rail welder incorporating an automatic burner swing device

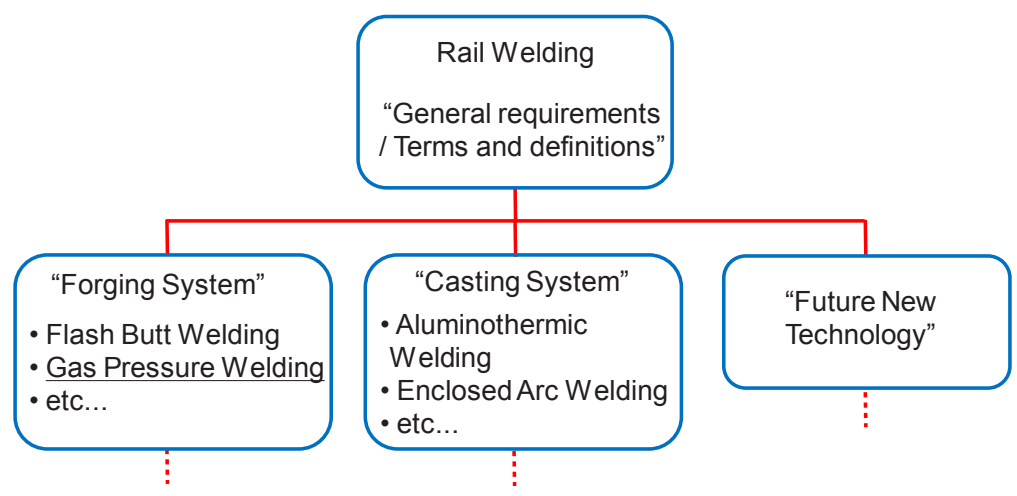

Fig. 5 Proposed structure of international standards for rail welding 
quality techniques at international meetings etc.[4]; and exhibiting the latest gas pressure rail welder (Fig. 6) incorporating an automatic burner actuation system that does not require expert skills at international trade fairs, such as the International Railway Equipment Exhibition in New Delhi.

\section{Conclusion}

As described above, five international standards development projects are underway for tracks as of 2018 , so that related support of tremendous amounts has been extended to our domestic committee members, working groups and international experts. In addition to those development projects, several track technologies such as turnout will be proposed. We would appreciate it if everyone concerned would keep paying attention to the ongoing rapid globalization of railway technology and extend further support to our international standardization efforts on tracks.

\section{References}

[1] Deshimaru, T., Tamagawa, S., Sonoda, Y. and Kataoka, H., "A Study on Verification Test Method for Rail Fastening Systems," Railway Engineering-2017, Edinburgh, UK, June 21-22, 2017.

[2] Deshimaru, T., Tamagawa, Kataoka, H. and S., Sonoda, Y., "A Study on Fatigue Test Conditions for Certification of Rail Fastening Systems," The 11th International Heavy Haul Conference, Cape Town, September 2-6, 2017.

[3] Tanaka, H., Matsumoto, M., Miwa, M. and Miyazaki, Y., "Comparison analysis of various evaluation indexes of track irregularity data for high-speed railway track," Railway Engineering-2017, Edinburgh, UK, June 2122, 2017.

[4] Yamamoto, R., "Rail Welding in Japan," The 11th International Heavy Haul Conference, Cape Town, September 2-6, 2017.

\section{Author}

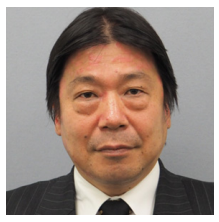

Katsumi MURAMOTO, Dr. Eng. Director, Track Technology Division Research Areas: Geotechnics, Ballasted-track, Ballastless-track 